OPEN ACCESS

Edited by:

XueWei Xu

Second Institute of Oceanography,

State Oceanic Administration, China

Reviewed by:

Mariano González-Castro,

Consejo Nacional de Investigaciones Cientificas y Técnicas (CONICET),

Argentina

Andrew Anthony David,

Clarkson University, United States

*Correspondence:

J. Antonio Baeza

jbaezam@clemson.edu

Specialty section: This article was submitted to

Marine Evolutionary Biology, Biogeography and Species Diversity,

a section of the journal

Frontiers in Marine Science

Received: 24 April 2018

Accepted: 13 July 2018

Published: 28 August 2018

Citation:

Baeza JA (2018) Sexual Selection and

Mixed Sex Expression: Adolescent

Protandry, Phenotypic Tradeoffs and

'Unconventional' Sex Allocation

Estimates in a

Protandric-Simultaneous Hermaphrodite.

Front. Mar. Sci. 5:260.

doi: 10.3389/fmars.2018.00260

\section{Sexual Selection and Mixed Sex Expression: Adolescent Protandry, Phenotypic Tradeoffs and 'Unconventional' Sex Allocation Estimates in a Protandric- Simultaneous Hermaphrodite}

\section{J. Antonio Baeza ${ }^{1,2,3 *}$}

'Department of Biological Sciences, Clemson University, Clemson, SC, United States, ${ }^{2}$ Smithsonian Marine Station at Fort Pierce, Fort Pierce, FL, United States, ${ }^{3}$ Departamento de Biología Marina, Facultad de Ciencias del Mar, Universidad Católica del Norte, Coquimbo, Chile

In protandric-simultaneous (PS) hermaphrodites, individuals invariably reproduce as males first and later in life as simultaneous hermaphrodites. In this study, the shrimp Lysmata wurdemanni (Gibbes, 1850) was used as a model to (i) test for the role of sexual selection (male-male competition) in explaining the early male phase and size-dependent sex allocation (SDSA) in PS hermaphrodites, (ii) examine the tradeoff between the male and female function in hermaphrodites, and (iii) determine if SDSA also takes place in the form of sex-specific behaviors and anatomical structures. In L. wurdemanni, male mating ability was size- and sex-dependent; greater for small than for large hermaphrodites and for males than hermaphrodites matched in body size. The above explains the adaptive value of the early male phase in PS hermaphrodites; small individuals should speed up sperm production and delay female reproduction to profit from male mating opportunities that are the greatest when small. Size-dependent male mating ability also suggests that small hermaphrodites should produce proportionally more sperm than ova compared to large hermaphrodites, a prediction supported by data. Sex allocation, measured as sex-specific behaviors and anatomical structures, was also size-dependent. No tradeoff between ova and sperm mass was found. However, among-individual variation in resource acquisition was considerable, suggesting that the observed lack of a statistical relationship between sperm and ova mass does not necessarily imply the absence of sex allocation tradeoffs in L. wurdemanni. Sexual selection is most relevant in PS hermaphrodites, SDSA also involves sex-specific behaviors, and morphological features, and variation in resource acquisition and allocation can explain the apparent absence of sex allocation tradeoffs.

Keywords: sexual selection, sex allocation, hermaphrodite, shrimp, crustacea 


\section{INTRODUCTION}

The importance of sexual selection in shaping individual traits (e.g., anatomical, physiological, and behavioral) and population parameters (e.g., sex ratio, sexual dimorphism, migration, life history schedules) is well established in gonochoristic species (separate sexes) and, to a lesser extent, in strictly sequential and simultaneous hermaphrodites [separate sexes (Emlen and Oring, 1977; Andersson, 1994; Shuster and Wade, 2003), hermaphrodites (Warner et al., 1975; Arnqvist and Rowe, 2005; Koene, 2006; Leonard, 2006; Michiels and Koene, 2006; Munday et al., 2006; Petersen, 2006; West, 2009; Schärer and Pen, 2013)]. In contrast, sexual selection and its evolutionary consequences remain ill-explored in organisms with mixed sexual systems [for exceptions see (Lorenzi et al., 2006; Weeks et al., 2006, 2014; Baeza, 2007a; Lorenzi and Sella, 2008; Benvenuto and Weeks, 2012)].

In animals, examples of mixed sexual systems include androdioecy [males coexist with hermaphrodites in a population: e.g., the conchostracan shrimp Eulimnadia texana (Zucker et al., 1997), the fish Kryptolebias marmoratus (Mackiewicz et al., 2006)], bidirectional sex change [individuals shift from one sex to the other more than once during lifetime: the fish Lythrypnus dalli (Mary, 1994) and Gobiodon histrio (Munday et al., 1998)] and size-dependent sex allocation (SDSA) in species initially classified as strict simultaneous hermaphrodites [investment to the sex functions shifts with body size in various fish and worms (Petersen and Fischer, 1996; Schärer et al., 2001; Vizoso and Schärer, 2007)]. Species with peculiar sex expression patterns provide a useful model to test predictions fundamental to sexual selection and sex allocation theories and to probe for the universality of sexual selection processes and consequences in animals.

A rare mixed sexual system that may have arisen from sexual selection processes is protandric-simultaneous hermaphroditism [called "adolescent protandry" sensu (Ghiselin, 1974) and "protandric cosexuality" sensu (Policansky, 1982)]. In these species, individuals consistently mature and reproduce initially as males and later in life, after attaining female function, turn to functional simultaneous hermaphrodites. Protandric simultaneous hermaphroditism has been experimentally confirmed in a polychaete worm (Premoli and Sella, 1995), a land snail (Tomiyama, 1996), a tunicate (Manriquez and Castilla, 2005), a symbiotic barnacle (Crisp, 1983) and marine shrimps belonging to the genera Lysmata, Exhippolysmata, and Parhippolyte (Baeza, 2009, 2013; Braga et al., 2009; Baeza et al., 2016a). Protandric simultaneous hermaphroditism is also suspected in other taxa [e.g., fish, snails, barnacles (Ghiselin, 1969, 1974; Fischer, 1981; Charnov, 1982, 1987; Policansky, 1982; Crisp, 1983; Michiels, 1998; Chaine and Angeloni, 2005)]. In these sequential-simultaneous hermaphrodites, sexual selection might be relevant to explain (i) the adaptive value of the adolescent male phase and (ii) the optimal investment to the male and female function (i.e., sex allocation) during the hermaphroditic phase. Sequential-simultaneous hermaphrodites also serve as model systems to (iii) test predictions at the core of life-history and sex allocation theories; i.e., trade-offs between the sex functions (Charnov, 1982, 1987; Stearns, 1992; Roff, 2002; West, 2009).

\section{The Adaptive Value of the Early Male Phase in Protandric-Simultaneous \\ Hermaphrodites}

One hypothesis accounting for the adaptive value of the early male phase in protandric-simultaneous hermaphroditism, here named the "size-and-sex male advantage" hypothesis, argues that male mating ability is sex- and size-dependent (Bauer, 2002; Baeza, 2006, 2007a). If small individuals that allocate energy exclusively to male function are more successful in inseminating female-role hermaphrodites than other small individuals allocating energy to both ova and sperm, then it is advantageous for hermaphrodites to invest more into male reproduction when small and to channel resources to the female function later in life, when their male mating ability has decreased substantially (Bauer, 2002; Baeza, 2007a). This hypothesis also posits that it does not pay (in terms of fitness) for individuals to turn from functional males into pure females when older and larger (as in strict sequential hermaphrodites) due to infrequent but reliable male mating opportunities later in life. Such rare but consistent male mating opportunities imply male fitness gains favoring allocation to the male function, to some extent, in larger, and older individuals (Baeza, 2007a). Previous studies testing for the adaptive value of protandric simultaneous hermaphroditism have focused on the importance of sex-dependent time commitments, sex-dependent energetic costs, and size-dependent mortality rates (Baeza, 2006). As yet, sexual selection has not been formally considered as a mechanism accounting for the adaptive significance of protandric simultaneous hermaphroditism.

\section{Sex Allocation During the Simultaneous Hermaphroditic Phase}

In protandric simultaneous hermaphrodites, sexual selection might have another important role in driving allocation to the male and female function during their terminal simultaneously hermaphroditic phase. Sexual selection (e.g., sperm competition) has been recognized as most relevant in shaping investment to sperm and ova in strict simultaneous hermaphrodites (Trouvé et al., 1999; Locher and Baur, 2000; Schärer and Ladurner, 2003; Tan et al., 2004; Schärer, 2009; Janicke et al., 2013, 2016). Theory predicts that simultaneous hermaphrodites should allocate proportionally more to male function when small than when large if their male mating ability is greater than that of large conspecifics (Baeza, 2007a). Size-dependent sex allocation permits hermaphrodites to profit from male mating opportunities that are the greatest at small body sizes (Baeza, 2007a,b,c). Although a few studies have demonstrated the relevance of particular sexual selection components in driving sex allocation in species with mixed sex allocation patterns (in the polychaete worms Ophyotrocha puerilis and O. diadema Lorenzi et al., 2006; Lorenzi and Sella, 2008; Schleicherová et al., 2010, in the clam shrimp E. texana Weeks et al., 2006, 2014; Benvenuto and Weeks, 2012, in the caridean shrimp Lysmata wurdemanni 
(Baeza, 2006, 2007a,b,c), more experimental work is needed to determine how important this process is in species with disparate sex expressions.

\section{Tradeoff Between Male and Female Functions and Sex Allocation Estimates}

The terminal (simultaneously hermaphroditic) phase of protandric-simultaneous hermaphrodites may also prove most useful for exploring predictions fundamental to sex allocation and life-history theories (Charnov, 1982; Stearns, 1992; Roff, 2002; West, 2009). A fundamental assumption in sex allocation theory is that hermaphrodites have a fixed pool of resources, and thus, allocation to one sex function should occur at the expense of the other (Charnov, 1982; Schärer et al., 2005; Schärer, 2009). A negative correlation between male and female gonad mass (once the effect of body size is removed) is used as evidence for a phenotypic tradeoff (Raimondi and Martin, 1991; De Visser et al., 1994; Trouvé et al., 1999; Schärer et al., 2005). Nevertheless, several empirical studies have failed to uncover a negative correlation between reproductive tissues [e.g., (Petersen, 1990; Locher and Baur, 2000; Schärer and Ladurner, 2003; Jordaens et al., 2006; Baeza, 2007a; Hart, 2016); but see (Di Bona et al., 2014)]. Arguments explaining the absence of phenotypic tradeoffs include among-individual variation in resource acquisition and allocation [i.e., Y-model or acquisition-allocation model: (van Noordwijk and de Jong, 1986; de Jong, 1993)], allocation hierarchies: (Worley et al., 2003) and functional constraints: (Charlesworth, 1991), among others (Reznick, 1985). Among these, the most influential model that explains positive, negative, or no correlation between phenotypic male and female allocation in the presence of tradeoffs is the "Y-model" (van Noordwijk and de Jong, 1986; de Jong, 1993). This model argues that the covariance between two traits ultimately depends on the mean values and variances of resource acquisition and allocation to particular functions. When variation in acquisition is small and mean allocation to the sex functions is high, then a negative covariance between the sex functions is expected. However, when there is strong variability in acquisition, it is possible for the covariance between male and female allocation to be positive, giving the false impression, as measured by the statistical relationship between sperm and ova mass, that there is no tradeoff (Roff and Fairbairn, 2007).

An alternative (but not mutually-exclusive) explanation for the absence of a tradeoff between male and female function is that the tradeoff does exists but goes undetected because correlations between ovaries and testes mass cannot detect energy links between other components of the male and female function (Pease and Bull, 1988; Baeza, 2007a; Roff and Fairbairn, 2007). For instance, disproportional increases in allocation to ova mass might be occurring at the expense of male behaviors but not testes mass. Even assuming low variance in resource acquisition, a correlation between male and female gonad mass would fail to detect tradeoffs between gonad mass and behaviors. Thus, most critical to the study of sex allocation are the parameters used to describe reproductive investment (Charnov, 1982). As a convention, male versus female gonad mass is used as proxy for sex allocation [e.g., (Fischer, 1981; Strathmann et al., 1984; Petersen, 1990, 1991; Sella, 1990; Mary, 1994; Petersen and Fischer, 1996; Trouvé et al., 1999; Locher and Baur, 2000; Schärer et al., 2001; Baeza, 2007a,c; Vizoso and Schärer, 2007)]. Although gonad mass is 'straightforward' to measure, using it as a proxy for sex allocation estimates is problematic: the energetic and temporal costs of sperm and ova usually differ (Schärer and Robertson, 1999; Baeza, 2006, 2007a), and allocation to male or female function may take the form of investments in behaviors [i.e., mate searching: (Shuster and Wade, 2003; Baeza and Thiel, 2007)] or body structures [i.e., incubation chambers in brooding hermaphrodites: (Strathmann et al., 1984; Baeza, 2007b)]. These "unconventional" components of sex allocation are rarely measured [for exceptions, see (Lorenzi et al., 2006; Di Bona et al., 2014)]. Nevertheless, the accuracy of sex allocation estimates might improve considerably if investments other than gonad biomass are measured.

The aim of this study was three-fold. First, I experimentally tested for the importance of sexual selection in driving the early male phase characteristic of protandric simultaneously hermaphrodites, a rare type of mixed sexual system. The "sizeand-sex male advantage" hypothesis proposed in this study was tested while exploring the effect of sex and size on male mating success in a model species, which additionally allowed predictions to be made on shifts in sex allocation with body size for the terminal hermaphroditic phase. Thus, a second prediction on the optimal sex allocation of the terminal simultaneously hermaphroditic phase was tested using "conventional" (ova versus sperm mass) and "unconventional" (sex-specific behaviors and body structures) measures of sex allocation. Third and last, the theoretical phenotypic trade-off between male and female function was tested in the model species taking into account variation in resource acquisition and allocation experienced by individuals in the field. To accomplish the goals above, I used the marine caridean shrimp Lysmata wurdemanni (Gibbes, 1850) as a model.

\section{MATERIALS AND METHODS}

\section{Model Organism}

The marine shrimp L. wurdemanni was used as model because of the sizable amount of research which has been conducted on this protandric simultaneous hermaphrodite (Bauer and Holt, 1998; Bauer, 2002; Baeza and Bauer, 2004; Baeza, 2006, 2007a,b,c; Baeza, 2009; Baeza et al., 2009). In this species, juveniles invariably mature as male phase individuals (i.e., hereafter males). These males bear typical caridean male secondary characters and are only capable of reproducing as males, though their gonads are ovotestes (Bauer and Holt, 1998). Males later attain the female sex function developing into functional simultaneous hermaphrodites (i.e., hereafter hermaphrodites). Externally, hermaphrodites resemble females of caridean gonochoric species, brooding embryos in an abdominal chamber (Bauer and Holt, 1998; Baeza, 2007a). However, hermaphrodites retain testicular tissue, male ducts and gonopores, and thus have the ability to reproduce as both male and female (Bauer and Holt, 1998). Hermaphrodites can mate as 
males frequently, but copulation with another hermaphrodite is not reciprocal: i.e., a newly molted pre-spawning hermaphrodite copulates as a female, with a male or another hermaphrodite that acts only as male at that time. A sperm mass is attached to the underside of the pre-spawning hermaphrodite by a mating partner during copulations that last a few seconds (Bauer and Holt, 1998). Sperm from a mating is used to fertilize only eggs released during the spawning event that occurs $2-3 \mathrm{~h}$ later. There is no long-term sperm storage in this shrimp. After becoming hermaphrodites, individuals do not revert to their initial sexual condition and no self-fertilization has been demonstrated (Bauer, 2002).

\section{Collection and Maintenance of Shrimps}

Individuals of L. wurdemanni were collected from the rock jetty at Mustang Island, Port Aransas, Texas $\left(27.8339^{\circ} \mathrm{N}, 97.0611^{\circ} \mathrm{W}\right)$ between May 2004 and September 2006 and between June 2016 and September 2016 and transported in plastic bags filled with bubbling seawater to the laboratory of the University of Louisiana at Lafayette, LA or Clemson University, SC. In the laboratory, individuals were maintained prior to the experiments in 80 - $\mathrm{L}$ or $114-\mathrm{L}$ recirculating aquaria at a water temperature of $21-25^{\circ} \mathrm{C}$, 34-35 ppt salinity, and a light:dark cycle of 14:10 h. Shrimp were fed daily (ad libitum Wardley Shrimp Pellets, Hartz Mountain Corp., Secaucus, NJ).

\section{The Effect of Size and Sex Morph on Male Mating Ability}

In L. wurdemanni, the few studies exploring male mating ability have not controlled for size when testing the effect of sex morph, or for sex morph when testing the effect of size (Bauer, 2002; Zhang and Lin, 2005; Baeza, 2007b). Experiments using shrimp matched in size but from different sex morphs are needed to demonstrate an effect of sex in male mating ability (e.g., controlling for size). Similarly, experiments using shrimp of different sizes but of the same sex morph (e.g., small versus large hermaphrodites) can demonstrate an effect of body size in male mating ability.

The null hypotheses of no effect of body size and sex in the male mating ability of L. wurdemanni were tested in the laboratory when videotaping shrimp pairs of different sizes or sex morphs when competing for inseminating a third hermaphroditic shrimp ready to molt and reproduce as female [i.e., called a "parturial" shrimp (Bauer and Holt, 1998)]. The two shrimps that competed against each other for inseminating the parturial hermaphrodite were either (1) one small male (below average size; $<9.0 \mathrm{~mm}$ carapace length $\mathrm{CL}$ ) and one large hermaphrodite (above average size), or (2) one small and one large hermaphrodite, or (3) one small male and small hermaphrodite matched in body size $(<0.8 \mathrm{~mm}$ difference in CL between competing shrimp). All shrimps used during the experiments were sexually mature with respect to male function (larger than $6.0 \mathrm{~mm}$ CL (Baeza, 2006, 2007a,c).

In each experiment, the two male-role shrimp (competing for inseminating the third parturial shrimp) were first placed into an aquarium $(20 \mathrm{~L})$ for an acclimatization period of at least $2 \mathrm{~h}$. Next, the parturial hermaphrodite was placed into the same aquarium. The identity of the shrimp inseminating this "parturial" hermaphrodite was recorded either with a Brinno High Dynamic Range Time Lapse Camera - TLC200 Pro (speed of 10 frames second $^{-2}$ ) or Cohu CCD surveillance video camera connected to a time-lapse video recorder (GYRR model TLC1400, speed of 5 frames second ${ }^{-2}$ ). In the two cases, I used 6-mm or $8-\mathrm{mm}$ lenses sensitive to both low-intensity white and infrared light. Fluorescent and infrared $(880 \mathrm{~nm})$ lamps provided day and night illumination, respectively. Thirty independent replicates with different individuals in each mating trial were conducted during this experiment.

Differences in mating ability between male-role shrimps were detected when comparing the observed distribution of inseminations between competing male-role shrimps with the binomial random distribution, which, in the case of no significant difference, indicated no differences in male mating ability between male-role shrimps (Wilson and Hardy, 2002). During the experiment, I observed insemination of female-role shrimp by male-role shrimps occurring either exactly during the moment in which female-role shrimps were molting (i.e., when the "parturial" female-role hermaphrodite was restricted in its movements while emerging from its older molt carcass, and thus, the parturial individual did not have the opportunity to react to [i.e., "repeal"] male advances), or when the parturial hermaphrodite was swimming (i.e., seconds after molting and emerging from its older carcass, and thus, when parturial hermaphrodites were capable of repealing male advances; Baeza, 2007a,b,c; Baeza et al., 2009). Female-role hermaphrodites can avoid male advances using an "escape response" (i.e., a backward "tail” [= abdominal] flipping) that rapidly propel shrimp away from potential mating partners [(Baeza, 2007a,b,c; Baeza et al., 2009), unpublished data]. Thus, I compared the mating ability of male-role shrimps using the entire number of replicates, those replicates in which insemination occurred during the moment in which parturial hermaphrodites were molting, and those replicates in which insemination occurred after molting of the parturial hermaphrodite. I expected to gain knowledge on the putative role of female-role shrimps behaviors in affecting insemination efficiency by classifying the experimental replicates in the three categories above. The significance level of the different tests was established by a binomial exact test using the software JMP v.12 (SAS., 2014). Lastly, there is strong evidence that the male mating ability of small shrimps is greater than that of large shrimps as shown by various previous experimental studies (Baeza, 2007a,b,c). Given the strong indication of a directional effect of body size in male mating ability (small $>$ large) I decided to use one-tailed $\chi^{2}$ test when detecting differences in male mating ability between male-role shrimps in the first two experiments [see (Ruxton and Neuhäuser, 2010)].

If the male mating ability of small shrimp is greater than that of large shrimp, then parturial hermaphrodites will be inseminated by small shrimp (either males or hermaphrodites) more often than expected by chance alone (i.e., 50\% of the times). If sex morph affects male mating ability, then parturial hermaphrodites will be inseminated by males or hermaphrodites more frequently than expected by chance alone in the experiment in which shrimp were matched in size. 


\section{Sex Allocation in Simultaneous Hermaphrodites}

As a convention, sex allocation is measured as male versus female gonad mass (Fischer, 1981; Sella, 1990; Petersen, 1991; Mary, 1994; Petersen and Fischer, 1996; Trouvé et al., 1999; Locher and Baur, 2000; Schärer et al., 2001; Baeza, 2007a,c; Vizoso and Schärer, 2007). Studies that have measured 'unconventional' components of sex allocation; investments in behavior and body structures specific to male or female function, are rare [e.g., (Lorenzi et al., 2006)]. Here, one conventional and two unconventional sex allocation components were measured: (1) ovaries versus testes mass, (2) investment in behaviors, and (3) body structures, respectively.

\section{Conventional Sex Allocation}

Conventional sex allocation was estimated as in (Baeza, 2007a). Sex allocation was quantified in a total of 20 hermaphrodites transported alive to the laboratory after collection. Sperm mass, testes mass, hepatopancreas and ovaries mass were measured. Sperm mass contained in the ejaculatory ducts (that serve as reservoirs of their own sperm in shrimps) was retrieved by electro-ejaculation [by applying short electric shocks at 10-12 volts for about $2-5 \mathrm{sec}$ near the male gonopores as in (Baeza, 2007a)]. Next, each shrimp was dissected to extract the hepatopancreas and ovarian and testicular portions of its ovotestes. Finally, shrimp and their hepatopancreas, ovaries, sperm mass, and testes were dried for $48 \mathrm{~h}$ at $70^{\circ} \mathrm{C}$ in an oven (Grieve Co., LO-201C), and weighed to the nearest $0.01 \mathrm{mg}$ with an analytical balance (Mettler AE163).

From the measurements above, four different estimates of reproductive allocation were calculated. Allocations to female and male function were estimated as the dry weight of embryos and sperm contained in the ejaculatory ducts, respectively. Total reproductive investment was estimated as the sum of the male and female allocations and represents the absolute amount of resources that individuals invest in reproduction. Sex allocation was estimated as the ratio of female to male allocation and represents the relative proportion of resources that individuals invest in functioning as the different sexes.

I tested whether the four estimates of reproductive allocation above increased linearly with body size of hermaphrodites. The relationship between total reproductive investment, male allocation, female allocation, or sex allocation and body dry mass of hermaphrodites was examined using the allometric model $y=\mathrm{ax}^{\mathrm{b}}$ (Klinkhamer et al., 1997). The slope $\mathrm{b}$ of the log-log least-squares linear regression represents the rate of exponential increase $(b>1)$ or decrease $(b<1)$ of the different estimates of reproductive allocation with shrimp dry mass (Schärer et al., 2001; Baeza, 2006). To determine if the relationship deviates from linearity, an F-test was used to test if the estimated slope b deviates from the expected slope of unity (SAS., 2011). For example, if total reproductive investment per body mass neither increases nor decreases with body size in L. wurdemanni, then the relationship should be linear with a slope not significantly different from unity. Evaluation of assumptions of normality (using residual quantile plots) and homogeneity of variances were checked and found to be satisfactory for each independent ANCOVA (see Supplementary Materials).

\section{Unconventional Sex Allocation: Behavior}

In the field, L. wurdemanni live in large crowds and laboratory observations demonstrate that the mating system of this species is pure-search polygamy; male-role shrimp explore the environment in search of receptive female-role shrimp that are intercepted, inseminated and then immediately abandoned (Baeza, 2007b,c). In this mating system, it is advantageous for males to roam around intensively as increasing activity augments the chance of finding female sexual partners (Shuster and Wade, 2003; Baeza and Thiel, 2007). Thus, roaming is here considered a behavior specific to the male function. In turn, during periods of inactivity (resting), females of gonochoric crustaceans attend their brood; grooming and oxygenating embryos (Förster and Baeza, 2001; Baeza and Fernández, 2002; Baeza et al., 2016b). In L. wurdemanni, hermaphrodites almost invariably brood embryos throughout the year (Baldwin and Bauer, 2003; Baeza, 2007a) and preliminary observations demonstrated that during these periods of inactivity, brooding hermaphrodites attend their embryos intensively (embryo oxygenation through pleopod beating: mean $[ \pm \mathrm{sd}]=39.8[ \pm 14.9]$ bouts hour ${ }^{-1}$; grooming embryos with cleaner claws: $104.8[ \pm 36.3]$ sec hour $\left.^{-1}[N=7]\right)$. Thus, inactivity was here considered a behavior related to the female function (brood attending). If hermaphrodites are investing proportionally more to roaming with increasing body size (and thus, allocation to male specific behaviors increases proportionally more with body size), then roaming should also increase proportionally more with body size (carapace length).

The null hypothesis of equal investment in roaming activity with increasing body size was tested by recording the behavior of pairs of hermaphrodites of different sizes in the laboratory. Two hermaphrodites were placed in the same aquarium: one small hermaphrodite (sexually mature but below average size; $6.0<$ $\mathrm{CL}<9.0 \mathrm{~mm}$ ) and one large hermaphrodite (above average size; $\mathrm{CL}>9.0 \mathrm{~mm}$ ) and their behavior was videotaped continuously over a 24 -h period using time-lapse video as in the previous experiment. Twenty two independent replicates with different individuals in each trial were conducted during this experiment. To avoid pseudoreplication, the behavior of a single shrimp randomly selected in each replicate was analyzed. Also, behavior was recorded only during the night (between 2100 and $0600 \mathrm{~h}$ ) because preliminary observations demonstrated that shrimp are not active by day. The proportion of time that selected shrimp spent roaming (either crawling or swimming) was recorded during two randomly selected time blocks of $1 \mathrm{~h}$ each.

The possibility of an asymmetric investment in male behavior (activity) with increases in body size was explored when searching for the model (i.e., linear, exponential) that best describes the effect of carapace length (CL) on activity (time crawling plus swimming per hour). The best model explaining the relationship between these variables was selected using an information theoretical approach (Burnham and Anderson, 1998, 2002). Selection among competing models was based on Akaike's Information Criterion [AIC, (Akaike, 1973)]. First, the residual sum of squares for each of three different models 
(see results) depicting the relationship between shrimp body size (CL) and activity were calculated using Proc NLIN (SAS., 2011). Because sample size was small (the ratio of observations to model parameters was less than 40), the corrected AIC value (AICc) was used to select the best model (Burnham and Anderson, 2002). Next, model likelihoods, model probabilities (AICc weights, $w_{i}$ ), and evidence ratios were calculated to provide quantitative measures of strength of evidence in favor of one model over another. The best model selected indicated whether hermaphroditic shrimp were investing proportionally less or more to male behavior with body size (to male function) with increasing body size.

\section{Unconventional Sex Allocation: Morphology}

In caridean shrimp with separate sexes, the pleura of the second abdominal segment is much enlarged in females than in males. This structure forms the lateral flanks of a chamber that protects the embryos (e.g., from physical abrasion) brooded by females under the abdomen (Bauer, 2004; Baeza, 2007a). Similarly, pleopod flanges are wider in females than in males because females maintain embryos within the chamber by attachment to long marginal setae (Höglund, 1943). Thus, abdominal pleura and pleopod flanges represent investment to female function in hermaphrodites of $L$. wurdemannni. If female allocation in terms of anatomical traits is size-dependent, then pleura and/or pleopod flanges should grow e.g., proportionally more with body size.

With respect to male anatomical traits, in shrimp, and other arthropods that exhibit pure-search polygamy as mating system (Baeza, 2007c; Espinoza et al., 2008), males but not females have long and developed antenna containing various types of sensilla responsible for the reception of pheromones (e.g., in shrimp: Bauer and Caskey, 2006; Zhang and Lin, 2006; Zhang et al., 2008). In L. wurdemanni, the first pair of antenna bifurcates into two flagella (Zhang et al., 2008). The proximal portion of the external flagellum bears numerous aesthetascs (cylindrical, annulated, unimodal chemo-sensilla, $100-800 \mu \mathrm{m}$ long by $9-$ $20 \mu \mathrm{m}$ diameter) (Zhang et al., 2008). These aesthetascs are important for male-role shrimp in detecting pheromones from receptive female-role hermaphrodites; removal of the lateral antennular flagellum and aesthetascs results in mating failure (Zhang and Lin, 2006). Thus, first and second antennae length and the length of the aesthetascs row represent investment to male function in L. wurdemanni. If male allocation in terms of anatomical traits is size-dependent, then antennae and aesthetasc row should grow more than proportional with increasing body size.

Tests were conducted to determine if total length of the first and second antenna, length of the accessory branch (aesthetascs row) in the second antenna, width of second abdominal pleura, and width of second pleopod were linearly related to body size of hermaphrodites. The relationship between the four structures above and carapace length $(\mathrm{CL}, \mathrm{mm})$ of hermaphrodites was examined using the allometric model $\mathrm{y}=\mathrm{ax}^{\mathrm{b}}$ (Hartnoll, 1978, 1982). The slope $b$ of the log-log least-squares linear regression represents the rate of exponential increase $(b>1)$ or decrease $(b<1)$ of different anatomical structures with shrimp carapace length. To determine if the relationship deviates from linearity, an $F$-test was used to test if the estimated slope b deviates from the expected slope of unity (SAS., 2011). For instance, if the second abdominal pleura grow more or less than proportionally with a unit increase in body size of shrimp, then the slope should be greater or smaller than the unity, respectively (Hartnoll, 1978).

\section{Tradeoff Between the Sex Functions}

The variance in resource acquisition, allocation, and their interaction [as considered in the Y-model (van Noordwijk and de Jong, 1986)] was used to predict the sign of the tradeoff between male and female function in hermaphrodites of $L$. wurdemanni. As proxy for resource acquisition, I used hepatopancreas and shrimp body mass. In crustaceans, including caridean shrimps, the role of the hepatopancreas in energy assimilation and storage is well known, and the relationship between hepatopancreas biomass and reproductive tissue usually shows an inverse relationship (Sagi and Rảanan, 1988; Hinojosa and Thiel, 2003). Thus, hepatopancreas is a reasonable proxy of acquisition (and variation) of resources directly related to reproduction (Roff and Fairbairn, 2007). On the other hand, a few studies have shown that lipid demands of ovarian maturation appear not to be met by substantial draw down of pre-existing lipid stores from the hepatopancreas [Hasek and Felder, 2005, and references therein]. Thus, I also used body mass as second proxy for resource acquisition because body size is expected to correlate well with energy intake; larger organisms have a larger budget to invest in reproduction than smaller organisms (Klinkhamer et al., 1997; Baeza, 2007a).

I calculated variances for resource acquisition (body mass or hepatopancreas mass) and allocation (ova and testes mass) from the same individuals for which sex allocation was quantified (see subsection Conventional sex allocation). Variances of hepatopancreas and ova and testes mass were calculated from the unstandardized residuals obtained by regressing hepatopancreas, ovary and testes mass on shrimp body mass. The expected sign of the covariance between male and female function $\left(\sigma_{X 1 X 2}\right)$ was calculated using Roff and Fairbairn's formula (Roff and Fairbairn, 2007):

$$
\sigma_{X 1 X 2}=1 / 2\left[\sigma_{T}^{2}-\left(\sigma_{f}^{2}+\sigma_{m}^{2}\right)\right]
$$

where, $\sigma^{2}$ is the variance in acquisition, $\sigma^{2}$ is the variance in male allocation and $\sigma_{\mathrm{f}}^{2}$ is the variance in female allocation. This equation predicts the sign of the covariance between male and female function taking into consideration the effect of relative variation in acquisition and in allocation (Roff and Fairbairn, 2007). I also calculated and reported the coefficient of variation of the different traits.

Lastly, I tested for the expected sign of the phenotypic covariance between male and female function predicted by Roff and Fairbairn's equation(Roff and Fairbairn, 2007) by calculating the partial correlation between ova and testes mass while controlling for shrimp body mass (SAS., 2011). 


\section{RESULTS}

\section{The Adaptive Value of}

\section{Protandric-Simultaneous Hermaphroditism}

Male mating ability is affected by body size and sex morph in $L$. wurdemanni. In the first experiment, small males were 5 times more successful in inseminating parturial shrimps than were large hermaphrodites acting as males (25 out of 30 , binomial exact test, $P_{\text {exact }}=0.0002$; Figure 1A). In 8 out of 30 replicates, insemination occurred during the moment of molting (i.e., when the "parturial" hermaphrodite was restricted in its movements while emerging from its older molt carcass), and in 7 out of these 8 replicates, the shrimp inseminating this "parturial" hermaphrodite was the small male. Small males inseminated the parturial shrimp more frequently than expected by chance alone when insemination occurred during the moment of molting $\left(P_{\text {exact }}=0.0352\right)$. In the remaining 22 replicates, mating occurred when the parturial hermaphrodite was swimming (i.e., seconds after molting and emerging from its older carcass), and in 18 out of these 22 replicates, the shrimp inseminating this "parturial" hermaphrodite was again the male $(P=0.0022)$.

In the second experiment where small and large hermaphrodites competed for insemination of the parturial shrimp, the small hermaphrodites inseminated the parturial shrimp more frequently than expected by chance alone (24 out of $30, P_{\text {exact }}=0.0007$; Figure 1B). Small hermaphrodites had higher mating success than large hermaphrodites when the insemination occurred during molting of the parturial shrimp (8 out of 8 observations). It was not possible to test whether or not small hermaphrodites inseminated parturial shrimps more frequently than expected by chance alone when insemination occurred during molting [no structural zeros are permitted in binomial tests (Wilson and Hardy, 2002)]. However, if a single large hermaphrodite would have inseminated the parturial shrimp at the moment of molting during this experiment, small males still would have inseminated the parturial shrimp more frequently than expected by chance alone $\left(P_{\text {exact }}=0.0352\right)$. In the remaining 22 replicates, mating occurred when the parturial hermaphrodite was swimming, and in 16 out of these 22 replicates, the shrimp inseminating this "parturial" hermaphrodite was again the small hermaphrodite $(P=0.0262)$.

In the third experiment where male and hermaphrodites were matched in size, males were 4 times more successful in inseminating parturial shrimp than were hermaphrodites acting as males ( 21 out of $30, P_{\text {exact }}=0.0263$; Figure 1C). In 8 out of 30 replicates, insemination occurred during the moment of molting, and in 5 out of these 8 replicates, the shrimp inseminating this "parturial" hermaphrodite was the small male. Although small males were nearly twice more successful in inseminating parturial shrimps than were male-role hermaphrodites when insemination occurred during the moment of molting, no significant difference was observed between males and hermaphrodites in male mating ability $(P=0.3633)$. The above is likely due to the small number of times (samples) in which insemination occurred while the parturial hermaphrodite was still molting in this experiment. In the remaining 22 replicates, mating occurred when the parturial hermaphrodite was swimming, and in 16 out

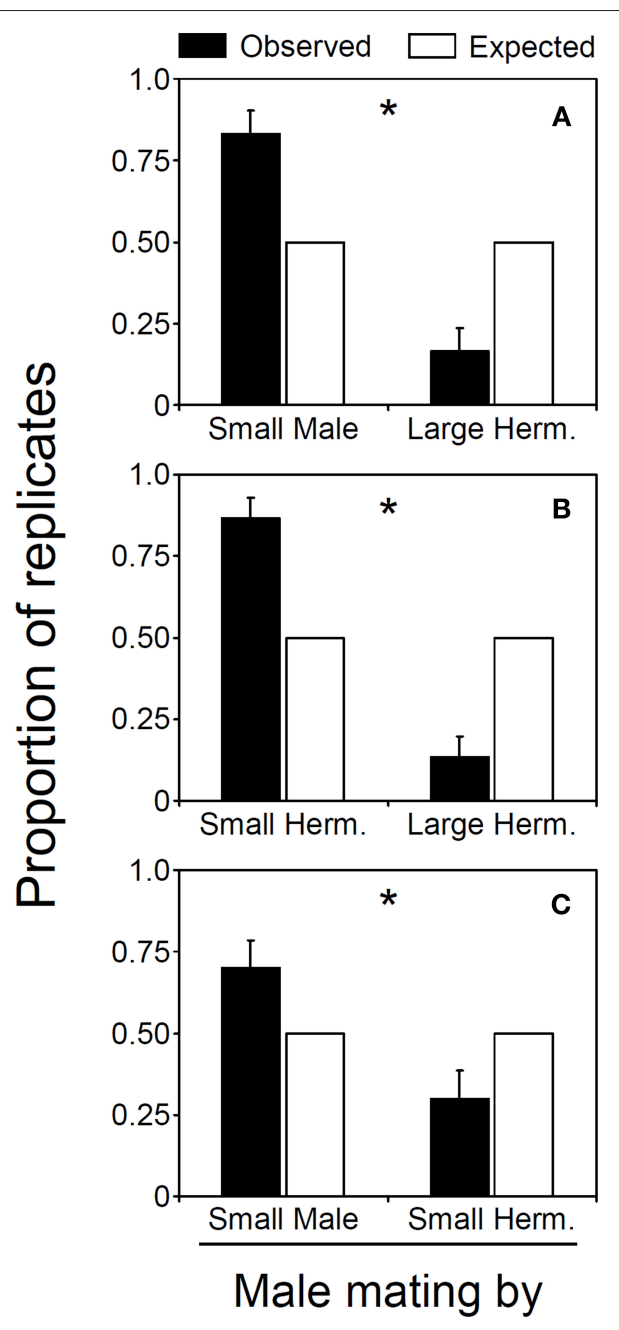

FIGURE 1 | Male mating ability of males and hermaphrodites in Lysmata wurdemanni. (A) small male versus large hermaphrodite. (B) small hermaphrodite vs large hermaphrodite. (C) small male versus small hermaphrodite. Observed and expected proportion of the replicates in which males or hermaphrodites inseminated parturial hermaphrodites. Error bars are binomial standard errors (for details see section Materials and Methods). Asterisks denote significant differences between observed and expected random mating ability.

of these 22 replicates, the shrimp inseminating this "parturial" hermaphrodite was again the male $(P=0.0299)$.

\section{Conventional Sex Allocation}

Sex allocation as measured in the present study is strongly female biased in L. wurdemanni. When the effect of body size was not taken into account, the ratio of female to male dry reproductive mass varied between 50.7 and 203.4 with an average ( \pm S.D.) of $122.6( \pm 37.5)$.

Sex allocation is also size-dependent in L. wurdemanni. Total reproductive output (ovaries, stored sperm, and testes mass) increased proportionally with increasing body size; the slope of the relationship between shrimp dry mass and total reproductive output dry mass did not differ significantly from 
unity ( $b=1.2, P=0.2634$; Table 1). Small hermaphrodites allocated proportionally more resources to male function compared to large hermaphrodites as the slope of the relationship between shrimp dry mass and sex allocation was smaller than unity $(b=0.56 ; P=0.0069$; Table 1). Interestingly, the slope of the relationship between shrimp dry mass and ovaries dry mass did not deviate significantly from unity ( $b=1.19, P=0.2634$ : Table 1), while the slope of the relationship between shrimp dry mass and testes plus sperm stored at the ejaculatory ducts was significantly smaller than unity ( $b=0.56, P=0.0225$; Table 1). Thus, hermaphrodites allocated proportionately to female reproduction but disproportionately less to male reproduction with increasing body size (Table 1).

\section{Unconventional Sex Allocation: Behavior}

Hermaphrodites spend disproportionately more time roaming around when small than when large. Visual examination of the data indicated that the relationship between shrimp body size and activity was negative and that was best described either by a nonlinear exponential model (Figure 2). The $\mathrm{AIC}_{\mathrm{c}}$ values calculated for three different models (i.e., null model only with an intercept, linear model including intercept and slope, exponential model including intercept and slope) indicated that the exponential model including intercept and slope was the best depicting the relationship between the two studied variables. The evidence ratio indicated that the non-linear model was 2.48 times more supported by the data than the linear model (Table 2).

\section{Unconventional Sex Allocation: Morphology}

Hermaphrodites invested proportionally less in body structures specific to male functioning with increasing body size. In turn, hermaphrodites invested either proportionally or proportionally less in body structures specific to female functioning with increasing body size (Table 3; Figure 3). A positive correlation between body size of shrimp and the different morphological variables was detected for hermaphroditic shrimp $(P<0.001$ in all cases). However, the different structures differed with respect to the status and degree of allometry (Table 3 ). The second abdominal pleura (female character) grew proportionally

TABLE 1 | Reproductive measurements and their relationship with body size in Lysmata wurdemanni.

\begin{tabular}{|c|c|c|c|c|c|c|c|}
\hline \multirow[t]{2}{*}{ Dep. Variable } & \multicolumn{3}{|c|}{ Model } & \multicolumn{2}{|c|}{ Test $H_{0}: b=0$} & \multicolumn{2}{|c|}{ Test $H_{0}: b=1$} \\
\hline & $r^{2}$ & $b$ & SE & $\boldsymbol{F}_{(1,18)}$ & $P$ & $F_{(1,18)}$ & $P$ \\
\hline Reprod. output & 0.73 & 1.20 & 0.17 & 49.17 & $<0.0001$ & 1.33 & 0.2634 \\
\hline Fem. allocation & 0.73 & 1.19 & 0.17 & 49.17 & $<0.0001$ & 1.33 & 0.2633 \\
\hline Male allocation & 0.35 & 0.56 & 0.18 & 9.89 & 0.0056 & 6.23 & 0.0225 \\
\hline Sex allocation & 0.47 & 0.56 & 0.14 & 16.55 & 0.0007 & 9.31 & 0.0069 \\
\hline
\end{tabular}

The adjusted coefficient of determination $\left(r^{2}\right)$, the slope (b) of the curve denoting the relationship between a particular measurement and body size of shrimp, and the standard error (SE) of the estimated slope are provided for each specific reproductive measure. Also, the F-statistic and the corresponding P-value obtained when testing for a positive correlation for linearity between a particular reproductive measurement and body size are presented. with body size; the slope of the relationship between shrimp body size and pleura did not differ from unity (Figure 3). In contrast, the remaining body structures showed negative allometry; the slope of the relationship between shrimp body size and the size of the base of the second pleopod (female character), the first and second antennae (male character), and the accessory branch (male character) differed significantly from unity (Table 3; Figure 3).

\section{Tradeoff Between Sex Functions}

Variation in acquisition, either based on hepatopancreas or body mass was moderate $(\mathrm{CV}=31-40 \%)$ and the magnitude of this variation was similar to that of allocation to male and female function (measured as sperm and ova mass, respectively; $\mathrm{CV}=28-45 \%$; Table 4). The relationship between the different variances, as depicted by Roff and Fairbairn's equation (Roff and Fairbairn, 2007), predicts that the sign of the covariance between male and female allocation should be either negative or positive but only marginally, depending on whether the proxy used for resource acquisition was hepatopancreas or body mass, respectively (Table 4 ).

In agreement with the prediction above about the sign and direction of the covariance between male and female function, female allocation was not statistically correlated with male allocation when shrimp body weight was accounted for (Figure 4; Table 4).

\section{DISCUSSION}

\section{The Adaptive Value of}

Protandric-Simultaneous Hermaphroditism

In the protandric simultaneous hermaphroditic shrimp $L$. wurdemanni, I found that male mating ability is affected by body size and sex phase. The importance of body size in affecting

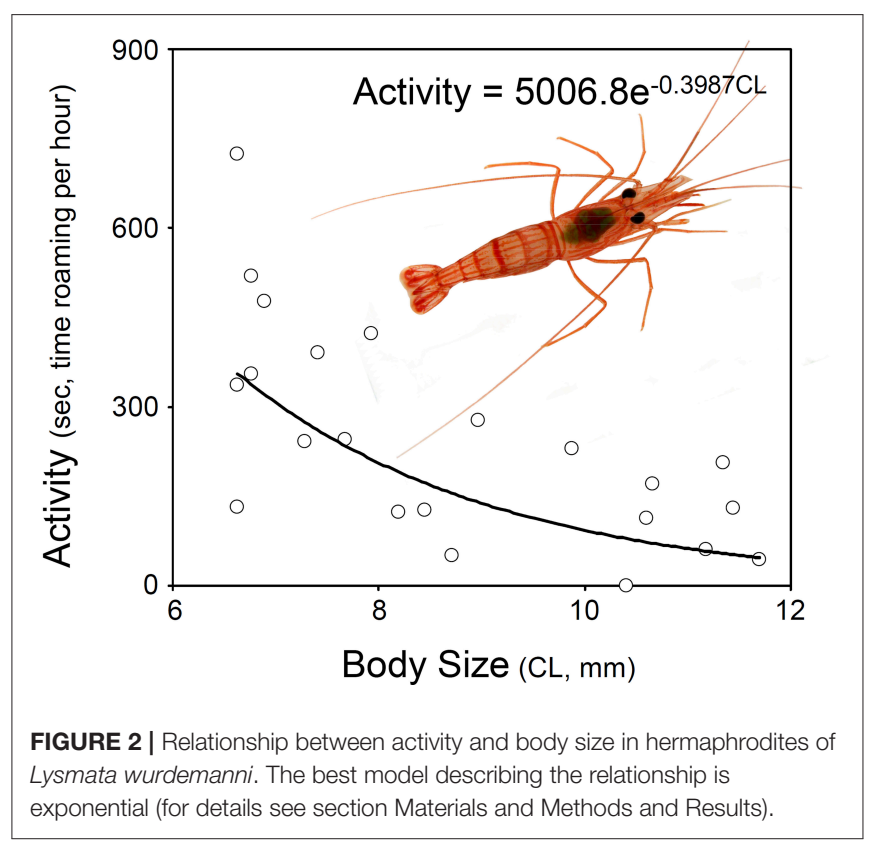


TABLE 2 | Summary of model selection results for the relationship between activity and body size in hermaphroditic shrimp of $L$. wurdemanni.

\begin{tabular}{lcccccc}
\hline Model & Parameters & $\boldsymbol{N}$ & $\mathbf{A l C}_{\mathbf{c}}$ & $\boldsymbol{\Delta}(\mathbf{M})$ & $\boldsymbol{w}_{\boldsymbol{i}}$ & Rank (M) \\
\hline Null & 1 & 22 & 230.10 & 12.70 & 0.0013 & 3 \\
Linear & 2 & 22 & 219.28 & 1.89 & 0.2796 & 2 \\
Exponential & 2 & 22 & 217.39 & 0 & 0.7191 & 1
\end{tabular}

For each model, the number of parameters in the model, $A / C_{C}$ value, likelihood $[\Delta(M)]$, the difference between a particular model and the model with the minimum AIC value found), probability $\left(w_{i}\right)$ an ranking, are shown.

the outcome of competition for mates is well established in gonochoric species [e.g., large male advantage in the shrimp Rhyncocinetes typus (Correa et al., 2000)], has been examined in a few strictly sequential hermaphrodites [large male advantage in the protandric shrimp Pandalus latirostris (Chiba et al., 2000)], but it is poorly explored in species with mixed sexual systems (Lorenzi et al., 2006; Weeks et al., 2006, 2014; Baeza, 2007a,c; Lorenzi and Sella, 2008; Benvenuto and Weeks, 2012). In contrast to reports in other gonochoric and protandric species, small $L$. wurdemanni shrimps had a male mating advantage. Differences in mate searching efficiency (Andersson, 1994; Baeza and Thiel, 2007) and/or swimming ability (Baeza, 2007c) between small and large shrimps might explain this small male advantage. The conditions explaining sex- and size-specific male mating success in L. wurdemanni warrant further study. Yet, the results of the present study agree with predictions of the "size-andsex male advantage" hypothesis that explains the adaptive value of protandric simultaneous hermaphroditism. It should pay (in terms of fitness) for individuals of L. wurdemanni to speed up maturation of the male function and delay female reproduction until later in life to profit from male mating opportunities that are the greatest when small and when ovaries have not yet developed. Previous studies have demonstrated the importance of natural selection processes, including sex-dependent time commitments, sex-dependent energetic costs, and size-dependent mortality in favoring protandric simultaneous hermaphroditism (Baeza, 2006, 2007a; Baeza et al., 2009). For instance, the energetic burden of the female function coupled with resource constraints for small individuals, as experimentally demonstrated in $L$. wurdemanni (Baeza, 2006), should favor early maleness in hermaphrodites; sperm is cheaper to produce than ova when food is limited and the scope for growth large (Charnov, 1982; Klinkhamer et al., 1997; Baeza, 2006, 2007a). The present study demonstrates that sexual selection (i.e., malemale competition) is most relevant in species with mixed sexual systems accounting for the early male phase of protandricsimultaneous hermaphrodites.

The "size-and-sex male advantage" hypothesis also argues that infrequent but reliable male mating opportunities at large body sizes constrain large individuals to become pure females, in contrast to what happens in strictly protandric hermaphrodites (Charnov, 1982). Supporting this notion, large male-role hermaphrodites consistently obtained $17-20 \%$ of the inseminations when competing either against small males or small hermaphrodites in the laboratory [also, 20\% in
TABLE 3 | Body structures and their variation with body size in Lysmata wurdemanni.

\begin{tabular}{|c|c|c|c|c|c|c|c|}
\hline \multirow[t]{2}{*}{ Dep. Variable } & \multicolumn{3}{|c|}{ Model } & \multicolumn{2}{|c|}{ Test $H_{0}: b=0$} & \multicolumn{2}{|c|}{ Test $H_{0}: b=1$} \\
\hline & $r^{2}$ & b & SE & $\boldsymbol{F}_{(1,31)}$ & $P$ & $\boldsymbol{F}_{(1,31)}$ & $P$ \\
\hline \multicolumn{8}{|c|}{ FEMALE TRAITS } \\
\hline 2nd Pleura & 0.91 & 0.95 & 0.050 & 320.06 & $<0.0001$ & 0.89 & 0.3521 \\
\hline 2nd Pleopod & 0.84 & 0.84 & 0.035 & 255.07 & $<0.0001$ & 161.25 & $<0.0001$ \\
\hline \multicolumn{8}{|l|}{ MALE TRAITS } \\
\hline 1st Antenna & 0.40 & 0.73 & 0.044 & 82.48 & $<0.0001$ & 179.48 & $<0.0001$ \\
\hline 2nd Antenna & 0.48 & 0.59 & 0.082 & 34.26 & $<0.0001$ & 40.54 & $<0.0001$ \\
\hline Acc. Branch & 0.76 & 0.82 & 0.065 & 139.00 & $<0.0001$ & 13.68 & 0.0008 \\
\hline
\end{tabular}

The adjusted coefficient of determination $\left(r^{2}\right)$, the slope (b) of the curve denoting the relationship between a particular measurement and body size of shrimp, and the standard error (SE) of the estimated slope are provided for each specific reproductive measure. Also, the F-statistic and the corresponding $P$ value obtained when testing for a positive correlation and for linearity between a particular reproductive measurement and body size are presented.

(Baeza, 2007b)]. Thus, it seems beneficial for individuals of $L$. wurdemanni to invest at least some energy to sperm when large to profit from few but reliable male mating opportunities. In addition to these mating opportunities, brooding constraints might be considered another selective force favoring sperm production in large individuals of L. wurdemanni (Heath, 1979; Strathmann et al., 1984; Baeza, 2007a). Hermaphrodites of $L$. wurdemanni lose $\sim 8-10 \%$ of their embryos while brooding because of space limitation within their abdominal incubation chamber (Baeza, 2006). Thus, large hermaphrodites are also expected to invest at least some energy to sperm instead of all to ova that will be wasted (a considerable proportion; Heath, 1979; Strathmann et al., 1984; Baeza, 2007a). Furthermore, because brood loss is relatively small and male mating opportunities are infrequent at large body size, large hermaphrodites should invest most resources to ova and few to sperm. In support of this idea, sex allocation was strongly female biased in hermaphrodites of $L$ wurdemanni, a finding that agrees with previous studies [hermaphrodites allocated 118 times more to female than to male function as reported in (Baeza, 2007a)]. Overall, brood loss and reliable but infrequent opportunities for male reproduction at large body sizes are important factors explaining the adaptive significance of a terminal simultaneous hermaphrodite phase in L. wurdemanni.

\section{Sex Allocation During the Simultaneous Hermaphroditic Phase}

In L. wurdemanni, small hermaphrodites were more successful in inseminating female-role shrimp than large hermaphrodites. This effect of size on male mating success should additionally favor size-specific sex allocation during this hermaphroditic phase. All else being equal, small hermaphrodites allocating proportionally more to male function compared to large hermaphrodites will profit from male mating opportunities that are the greatest when small during this ontogenetic phase (Charnov, 1987; Bauer, 2002; Baeza, 2007b). The observed SDSA in L. wurdemanni (estimated as gonad mass) supports 


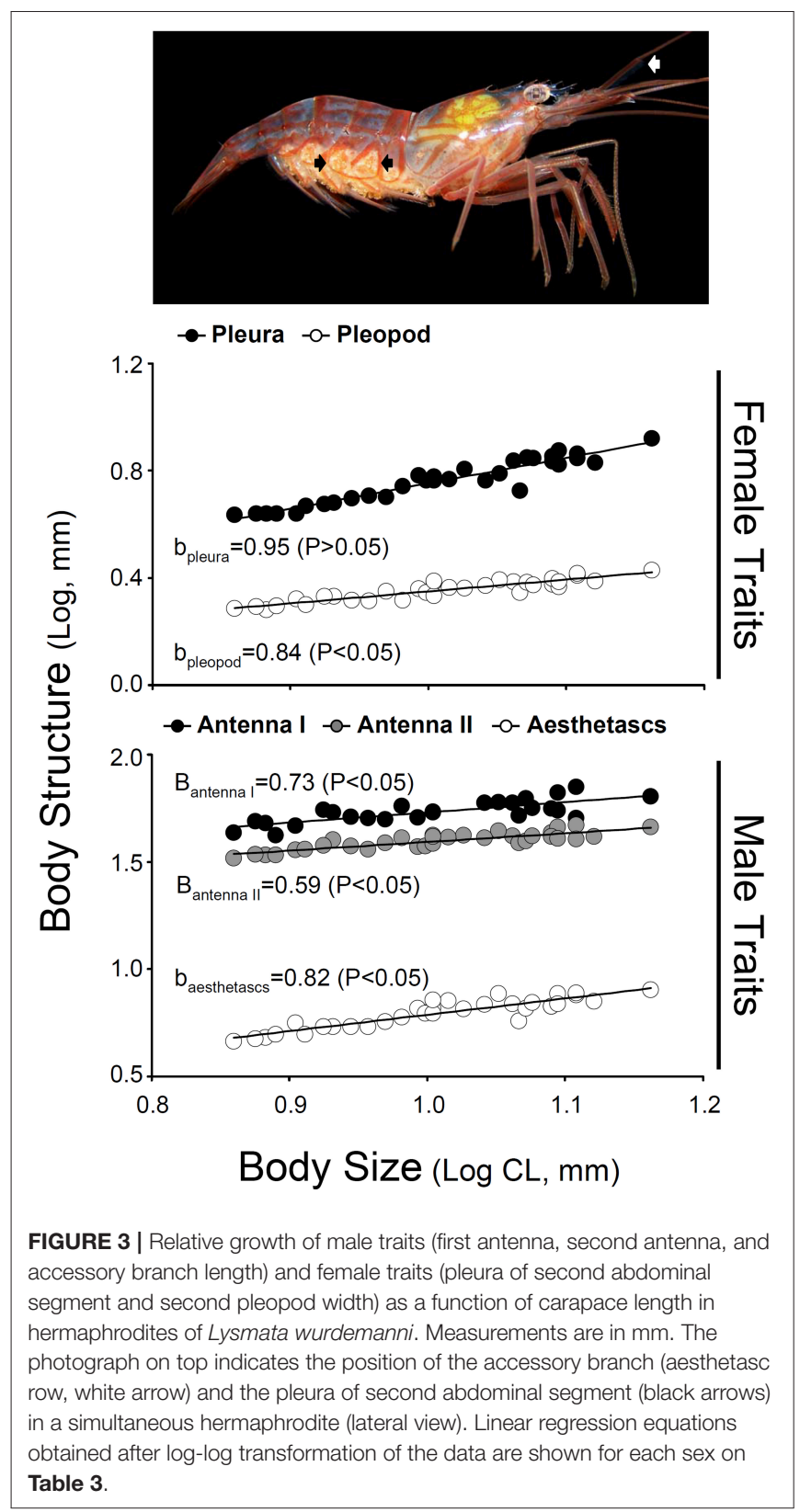

this prediction (Baeza, 2007a). Nevertheless, the effect of other conditions that depend directly or indirectly on the body size of hermaphrodites may be important determinants of SDSA in hermaphrodites. For instance, female-role hermaphrodites prefer to mate with small instead of large hermaphrodites (Baeza, 2007a). All else being equal, this preference for small male sexual partners is also expected to favor a large investment to sperm in small shrimp (Baeza, 2007a). Thus, this study demonstrate that sexual selection not only explains the adaptive value of protandric simultaneous hermaphroditism but also plays an important role in determining more subtle changes in investment throughout the lifetime of individuals.

In L. wurdemanni, sex allocation shifted with body size when measured as gonad mass but also in terms of behaviors
TABLE 4 | Variation in acquisition and investment, covariance between male and female function, and observed tradeoff between the sex functions in $L$. wurdemanni.

Parameters

Parameters

\begin{tabular}{lc}
\hline COEFFICIENTS OF VARIATION & \\
Body mass & 36.27 \\
Hepatopancreas & 34.54 \\
Male allocation & 33.64 \\
Female allocation & 45.66 \\
PREDICTED COVARIANCE & \\
Based on Hepatopancreas mass & $-8.79 \times 10^{-6}$ \\
Based on Body mass & 0.0021 \\
PHENOTYPIC CORRELATION & \\
Slope & 0.004 \\
SE & $2.38 \times 10^{-3}$ \\
N & 20 \\
$P$-value & 0.1094
\end{tabular}

Shown are: coefficient of variation (CV) for the different measurements, the predicted covariance between the sex functions depending on whether resource acquisition variance was based on hepatopancreas or shrimp body mass, and the slope, standard error (SE), sample size $(N)$ and associated P-value when testing for a tradeoff between male and female function. Variances in hepatopancreas, ova and testes mass were calculated from residuals using body mass.

and anatomical traits specific to male or female functions. Small hermaphrodites allocated proportionally more time to explore the environment than resting compared to large hermaphrodites. Here, roaming was considered a male behavior because exploration increases the chances of finding and inseminating female sexual partners (Andersson, 1994; Shuster and Wade, 2003; Baeza and Thiel, 2007; Duffy and Thiel, 2007) in species with pure-search mating systems as L. wurdemanni (Baeza, 2007c). It could be argued that roaming might be female and not male behavior because increasing foraging bouts should boost growth rate, speed up maturation of the ovaries and result in production of large broods later in life (Stephens and Krebs, 1986; Roff, 1992; Stearns, 1992). Nevertheless, in disagreement with this idea, large hermaphrodites that should experience strong energy requirements due to their remarkable investment to female reproduction (building up ovaries and attending embryos with energetically expensive behaviors Förster and Baeza, 2001; Baeza and Fernández, 2002; Baeza, 2006, were observed resting and not roaming around most of the time in the laboratory. In L. wurdemanni, swimming, and crawling around seems to be mostly a male behavior. Concomitant with the disproportional allocation to male exploratory behaviors, small hermaphrodites invested proportionally more to anatomical structures involved in chemoreception than large hermaphrodites [antennae and chemo-sensory sensilla (Zhang et al., 2008)]. Because sensilla are involved in early detection of receptive females (Zhang et al., 2008), the disproportional investment to these structures permit small hermaphrodites to profit from male mating opportunities that are the greatest when small (during this terminal phase). Overall, the present study demonstrates that shifts in sex allocation with size occur at various different levels, including morphological 


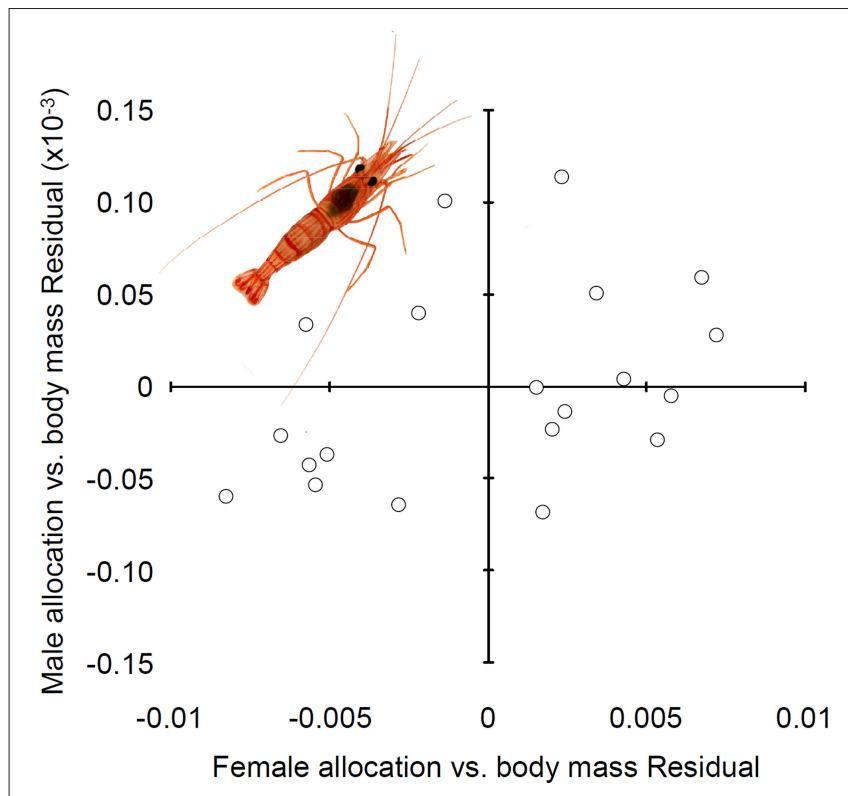

FIGURE 4 | Relationship between male and female allocation in hermaphrodites of Lysmata wurdemanni. All measurements are in grams (g) of dry mass.

and behavioral sex allocation traits, in hermaphrodites of L. wurdemanni.

In contrast to male sex-specific traits, anatomical structures related to female function (e.g., brooding) either increased linearly [second abdominal pleura: a structural component of the brooding chamber in caridean shrimps (Bauer, 2004)] or underwent a disproportional reduction with increases in shrimp size (e.g., pleopod flange: important for sustaining embryos in the brooding chamber-op. cit). Thus, in L. wurdemanni, hermaphrodites are investing proportionally to ovaries but not necessarily to anatomical structures related to female function (brooding) when growing. With regards to pleopod flange, in hindsight, this structure might represent a combined ("bisexual" or "unisex") female and male trait. Pleopods support eggs but also provide thrust for swimming (Bauer, 2004). Thus, pleopods might be becoming progressively smaller concomitant with reduced swimming activity in hermaphrodites. This study is one among a few [e.g., (Lorenzi et al., 2006)] demonstrating SDSA in terms of behavioral and anatomical components in species featuring mixed sex expression patterns.

\section{Tradeoff Between Male and Female Function and Sex Allocation Estimates}

In L. wurdemanni, the absence of a negative correlation between ova and sperm mass suggests, at first glance, the absence of a phenotypic tradeoff between male and female function [see also (Baeza, 2007a)]. Nevertheless, the calculation of proxies of resource acquisition and sex-specific investments predicted that the sign of the correlation between sperm and ova mass should be minimal and marginally positive or negative (van Noordwijk and de Jong, 1986; Roff and Fairbairn, 2007). In agreement with this prediction, the relationship between sperm and ova mass was not statistically significant and showed marginal positive or negative signs during this study. This study highlights the importance of examining variation in resource acquisition and allocation when testing for negative correlations between sperm and ova which in turn are used for deducing evolutionarily important functional tradeoffs (Roff and Fairbairn, 2007). If only the correlation between sperm and ova mass had been examined in this study, the absence of a phenotypic tradeoff between sex functions could have been concluded [as in (Baeza, 2007a)]. This finding had not been in agreement with one of the most fundamental assumptions of sex allocation theory (Charnov, 1982). This study is consistent with the notion that the interplay between resource acquisition and allocation might be such that even in the presence of a tradeoff between male and female function, it is not possible to find phenotypic covariance between male and female allocation in natural populations (van Noordwijk and de Jong, 1986; Roff and Fairbairn, 2007).

The study of variation in resource acquisition and allocation in L. wurdemanni supports the Y-model as an explanation for the sign of observed phenotypic tradeoffs, a finding that is in agreement with a few previous studies formally testing the Y-model with other traits [(Jordan and Snell, 2002; Brown, 2003); see also (Roff and Fairbairn, 2007) for critics]. Nevertheless, the effect of acquisition and allocation variation in the sign of the phenotypic correlations between sperm and ova mass does not exclude the idea of incompleteness of the "conventional" proxy of sex allocation i.e., ovaries versus testes mass (Petersen, 1990; Locher and Baur, 2000; Schärer and Ladurner, 2003; Baeza, 2007a) and its inadequacy to detect tradeoffs between different components of the sex functions (van Noordwijk and de Jong, 1986; Baeza, 2007a; Roff and Fairbairn, 2007). This study clearly demonstrated that, with increasing body size, there were disproportional decreases to male behaviors (exploration of the environment) and male anatomical traits (antennae). Thus, in L. wurdemanni, increases in allocation to ovaries mass might indeed be occurring at the expense of male anatomical structures and behaviors. This study highlights the importance of examining not a single but various (conventional and unconventional) components of sex allocation (sex-specific gonad mass, behaviors, and anatomical traits) that combined are closer to represent the overall reproductive investment of individuals. Future studies should measure sex allocation in conventional and unconventional terms and examine their variance to study the still ill-explored interconnection between different components of sex allocation and their network of tradeoffs between different behavioral and anatomical components.

\section{OUTLOOK}

This study is one among a few others demonstrating the importance of sexual selection in species with mixed sexual systems (Lorenzi et al., 2006; Weeks et al., 2006, 2014; Baeza, 2007a,b,c; Lorenzi and Sella, 2008; Benvenuto and Weeks, 2012). Male-male competition explains major changes in sex allocation with age/size of individuals and more subtle shifts in reproductive investment during the terminal hermaphroditic 
phase of a sequential-simultaneous hermaphrodite. This study also highlights the importance of measuring sex allocation in unconventional terms that improves considerably our knowledge of overall reproductive investments in hermaphrodites. Furthermore, my exploration of the variation in resource acquisition also helps understanding the absence of "phenotypic tradeoffs" that, at first glance, appear unsupportive of sex allocation theory. The model species L. wurdemani, belongs to a peculiar monophyletic clade of shrimps that exhibit an unusual sexual system (protandric simultaneous hermaphroditism) and a diverse socioecology (Baeza et al., 2007, 2009; Baeza, 2008, 2009; Baeza and Anker, 2008). Ongoing efforts are focusing in understanding sex ratio evolution and the role of sexual selection, cooperation, and conflict in driving the mating system and optimal sex allocation of species with mixed sexual systems.

\section{AVAILABILITY OF DATA AND MATERIALS}

Data is available in ResearchGate (https://www.researchgate.net/) as a single excel file.

\section{REFERENCES}

Akaike, H. (1973). Information Theory and an Extension of the Maximum Likelihood Principle. International Symposium on Information Theory, 2nd Edn. Budapest: Akademiai Kiado.

Andersson, M. (1994). Sexual Selection. Princeton, NJ: Princeton University.

Arnqvist, G., and Rowe, L. (2005). Sexual Conflict. Princeton, NJ: Princeton University.

Baeza, J. A. (2006). Testing three models on the adaptive significance of protandric simultaneous hermaphroditism in a marine shrimp. Evolution 60, 1840-1850. doi: 10.1111/j.0014-3820.2006.tb00527.x

Baeza, J. A. (2007a). Sex allocation in a simultaneously hermaphroditic marine shrimp. Evolution. 61, 2360-2373. doi: 10.1111/j.1558-5646.2007.00199.x

Baeza, J. A. (2007b). No effect of group size on sex allocation in a protandricsimultaneous hermaphroditic shrimp. J. Mar. Biol. Assoc. U.K. 87, 1169-1174. doi: $10.1017 /$ S0025315407057542

Baeza, J. A. (2007c). Male mating opportunities affect sex allocation in a protandric simultaneous hermaphroditic marine shrimp. Behav. Ecol. Sociobiol. 61, 365-370. doi: 10.1007/s00265-006-0265-2

Baeza, J. A. (2008). Protandric simultaneous hermaphroditism in the shrimps Lysmata bahia and L. intermedia. Inver. Biol. 127, 181-188. doi: $10.1111 / j .1744-7410.2007 .00122 . x$

Baeza, J. A. (2009). Protandric simultaneous hermaphroditism is a conserved trait in Lysmata (Caridea: Lysmatidae): implications for the evolution of hermaphroditism in the genus. Smithsonian Contrib. Mar. Sci. 38, 95-110.

Baeza, J. A. (2013). Multi-locus molecular phylogeny of broken-back shrimps (genus Lysmata and allies): a test of the 'Tomlinson-Ghiselin' hypothesis explaining the evolution of simultaneous hermaphroditism. Mol. Evol. Phyl.69, 46-62. doi: 10.1016/j.ympev.2013.05.013

Baeza, J. A., and Anker, A. (2008). Lysmata hochi n. sp., a new species of hermaphroditic shrimp from the southern Caribbean. J. Crustac. Biol. 28, 148-155. doi: 10.1651/07-2839R.1

Baeza, J. A., and Bauer, R. T. (2004). Experimental test of socially mediated sex change in a protandric simultaneous hermaphrodite, the marine shrimp Lysmata wurdemanni (Caridea: Hippolytidae). Behav. Ecol. Sociobiol. 55, 544-550. doi: 10.1007/s00265-003-0744-7

Baeza, J. A., and Fernández, M. (2002). Active brood care in Cancer setosus (Crustacea: Decapoda: Cancridae): the relationship between female behaviour,

\section{AUTHORS CONTRIBUTIONS}

JB conceived, designed and performed the experiments, analyzed the data, contributed with reagents, materials and analysis tools, and wrote the paper.

\section{ACKNOWLEDGMENTS}

Many thanks to M. Soledad Fuentes and Alexandra Valdez for their help with shrimp collections and other field and laboratory logistics. Many thanks to Katie Cramer that critically reviewed the English as well as the content of this manuscript and provided helpful comments. The experiments comply with the current laws of the United States of America. The author declares no conflict of interest.

\section{SUPPLEMENTARY MATERIAL}

The Supplementary Material for this article can be found online at: https://www.frontiersin.org/articles/10.3389/fmars. 2018.00260/full\#supplementary-material embryo oxygen consumption, and the cost of brooding. Funct. Ecol. 16, 241-251. doi: 10.1046/j.1365-2435.2002.00616.x

Baeza, J. A., Guéron, R., Simpson, L., and Ambrosio, L. J. (2016a). Population distribution, host-switching, and chemical sensing in the symbiotic shrimp Lysmata pederseni: implications for its mating system in a changing reef seascape. Coral. Reefs. 35, 1213-1224. doi: 10.1007/s00338-016-1467-3

Baeza, J. A., Reitz, J., and Collin, R. (2007). Protandric simultaneous hermaphroditism and sex ratio in the shrimp Lysmata nayaritensis. J. Nat. Hist. 41, 2843-2850. doi: 10.1080/00222930701770778

Baeza, J. A., Schubart, C. D., Zillner, P., Fuentes, S.,., and Bauer, R. T. (2009). Molecular phylogeny of shrimps from the genus Lysmata (Caridea: Hippolytidae): the evolutionary origins of protandric simultaneous hermaphroditism and pair-living. Biol. J. Linnean Soc. 96, 415-424. doi: 10.1111/j.1095-8312.2008.01133.x

Baeza, J. A., Simpson, L., Ambrosio, L. J., Mora, N., and Childress, M. (2016b). Active parental care, reproductive performance, and a novel egg predator affecting reproductive investment in the Caribbean spiny lobster Panulirus argus. BMC Zool. 1:6. doi: 10.1186/s40850-016-0006-6

Baeza, J. A., and Thiel, M. (2007). "The mating system of symbiotic crustaceans. A conceptual model based on optimality and ecological constraints," in Reproductive and Social Behavior: Crustaceans as Model Systems, eds J. E. Dufy and M. Thiel (Oxford: Oxford University Press), 245-255.

Baldwin, A. P., and Bauer, R. T. (2003). Growth, survivorship, life span, and sex change in the hermaphroditic shrimp Lysmata wurdemanni (Decapoda: Caridea: Hippolytidae). Mar. Biol. 143, 157-166. doi: 10.1007/s00227-003-1043-6

Bauer, R. T. (2002). Test of hypotheses on the adaptive value of an extended male phase in the hermaphroditic shrimp Lysmata wurdemanni (Caridea: Hippolytidae). Biol. Bull. 203, 347-357. doi: 10.2307/1543577

Bauer, R. T. (2004). Remarkable Shrimps. Norman: Oklahoma University.

Bauer, R. T., and Caskey, J. L. (2006). Flagellar setae of the second antennae in decapod shrimps: sexual dimorphism and possible role in detection of contact sex pheromones. Inv. Rep. Dev. 49, 51-60. doi: 10.1080/07924259.2006.96 52193

Bauer, R. T., and Holt, G. J. (1998). Simultaneous hermaphroditism in the marine shrimp Lysmata wurdemanni (Caridea: Hippolytidae): an undescribed sexual system in the decapod Crustacea. Mar. Biol. 132, 223-235. doi: $10.1007 /$ s002270050388 
Benvenuto, C., and Weeks, S. C. (2012). Intersexual conflict during mate guarding in an androdioecious crustacean. Behav. Ecol. 23, 218-224. doi: 10.1093/beheco/arr178

Braga, A. A., López-Greco, L. S., Santos, D. C., and Fransozo, A. (2009). Morphological evidence for protandric simultaneous hermaphroditism in the caridean Exhippolysmata oplophoroides. J. Crustac. Biol. 29, 34-41. doi: $10.1651 / 08.3015 .1$

Brown, C. A. (2003). Offspring size-number tradeoffs in scorpions: an empirical test of the van Noordwijk and de Jong model. Evolution 57, 2184-2190. doi: 10.1111/j.0014-3820.2003.tb00397.x

Burnham, K. P., and Anderson, D. R. (1998). Model Selection and Inference: a Practical Information-Theoretic Approach. New York, NY: Springer-Verlag.

Burnham, K. P., and Anderson, D. R. (2002). Model Selection and Multimodel Inference: A Practical Information-Theoretic Approach. 2nd Edn. New York, NY: Springer-Verlag.

Chaine, A., and Angeloni, L. (2005). Size-dependent mating and gender choice in a simultaneous hermaphrodite, Bulla gouldiana. Behav. Ecol. Sociobiol. 59, 58-68. doi: 10.1007/s00265-005-0009-8

Charlesworth, B. (1991). The evolution of sex chromosomes. Science 251, 1030-1033. doi: 10.1126/science.1998119

Charnov, E. L. (1982). The Theory of Sex Allocation. Princeton, NJ: Princeton University.

Charnov, E. L. (1987). Sexuality and hermaphroditism in barnacles: a natural selection approach. Crustacean Issues 5, 89-103.

Chiba, S., Goshima, S., and Shinomiya, Y. (2000). Male-male competition selects for delayed sex change in the protandrous shrimp Pandalus latirostris. Mar. Ecol. Progr. Ser. 142, 1153-1157.

Correa, C., Baeza, J. A., Dupré, E., Hinojosa, I. A., and Thiel, M. (2000). Mating behaviour and fertilization success of three ontogenetic stages of male rock shrimp Rhynchocinetes typus (Decapoda: Caridea). J. Crustac. Biol. 20, 628-640. doi: 10.1163/20021975-99990086

Crisp, D. J. (1983). Chelonobia patula (Ranzani), a pointer to the evolution of the complemental male. Mar. Biol. Lett. 4, 281-294.

de Jong, T. J. (1993). Covariances between traits deriving from successive allocations of a resource. Funct. Ecol. 7, 75-83. doi: 10.2307/2389869

De Visser, J. A. G. M., Ter Maat, A., and Zonneveld, C. (1994). Energy budgets and reproductive allocation in the simultaneous hermaphrodite pond snail, Lymnaea stagnalis (L.): a tradeoff between male and female function. Am. Nat. 144, 861-867. doi: 10.1086/285712

Di Bona, V., Minetti, C., Trotta, V., Sella, G., and Lorenzi, M. C. (2014). A trade-off between traits that contribute to male and female function in hermaphrodites. Ethol. Ecol. Evol. 27, 79-92. doi: 10.1080/03949370.2014.880162

Duffy, J. E., and Thiel, M. (eds.). (2007). Evolutionary Ecology of Social and Sexual Systems: Crustaceans as Model. Oxford: Organisms Oxford University Press.

Emlen, S. T., and Oring, L. W. (1977). Ecology, sexual selection, and the evolution of mating systems. Science 197, 215-223. doi: 10.1126/science.327542

Espinoza, N. L., Thiel, M., Dupre, E., and Baeza, J. A. (2008). Is Hippolyte williamsi gonochoric or hermaphroditic? A multi-approach study and a review of sexual systems in Hippolyte shrimps. Mar. Biol. 155, 623-635. doi: 10.1007/s00227-008-1059-z

Fischer, E. A. (1981). Sexual allocation in a simultaneously hermaphroditic coral reef fish. Am. Nat. 117, 64-82. doi: 10.1086/283686

Förster, C., and Baeza, J. A. (2001). Active brood care in the anomuran crab Petrolisthes violaceus (Decapoda: Anomura: Porcellanidae): grooming of brooded embryos by the fifth pereiopods. J. Crustac. Biol. 21, 606-615. doi: 10.1163/20021975-99990162

Ghiselin, M. T. (1969). The evolution of hermaphroditism among animals. Q. Rev. Biol. 44, 189-208. doi: 10.1086/406066

Ghiselin, M. T. (1974). The Economy of Nature and the Evolution of Sex. Berkeley, CA: University of California.

Hart, M. K. (2016). Phenotypic plasticity in sex allocation and body size leads to trade-offs between male function and growth in a simultaneously hermaphroditic fish. Evol. Ecol. 30, 173-190. doi: 10.1007/s10682-0159804-5

Hartnoll, R. G. (1978). The determination of relative growth in crustacea. Crustaceana 34, 281-292. doi: 10.1163/156854078X00844

Hartnoll, R. G. (1982). "Growth,"in The Biology of Crustacea, ed L. G. Abele (New York, NY: Academic), 111-196.
Hasek, B. E., and Felder, D. L. (2005). Biochemical composition of ovary, embryo, and hepatopancreas in grapsoid crabs Armases cinereum and Sesarma nr. reticulatum (Crustacea, Decapoda). Comp. Biochem. Physiol. 140B, 455-463. doi: 10.1016/j.cbpc.2004.11.010

Heath, D. J. (1979). Brooding and the evolution of hermaphroditism. J. Theor. Biol. 81, 151-155. doi: 10.1016/0022-5193(79)90157-7

Hinojosa, I., and Thiel, M. (2003). Somatic and gametic resources in male rock shrimp, Rhynchocinetes typus: effect of mating potential and ontogenetic male stage. Anim. Behav. 66, 449-458. doi: 10.1006/anbe.2003.2220

Höglund, H. (1943). On the Biology and Larval Development of Leander squilla (L.) forma Typica De Man. Svenska Hydrografisk-Biologiska Kommissionens skrifter: Serie: biologi, 6:1-44.

Janicke, T., Marie-Orleach, L., De Mulder, K., Berezikov, E., Ladurner, P., Vizoso, D. B., et al. (2013). Sex allocation adjustment to mating group size in a simultaneous hermaphrodite. Evolution 67, 3233-3242. doi: 10.1111/evo.12189

Janicke, T., Sandner, P., Ramm, S. A., Vizoso, D. B., and Schärer, L. (2016). Experimentally evolved and phenotypically plastic responses to enforced monogamy in a hermaphroditic flatworm. J. Evol. Biol. 29, 1713-1727. doi: 10.1111/jeb.12910

Jordaens, K., Van Dongen, S., Temmerman, K., and Backeljau, T. (2006). Resource allocation in a simultaneously hermaphroditic slug with phally polymorphism. Evo. Eco. 20, 227-239. doi: 10.1007/s10682-006-9115-y

Jordan, M. A., and Snell, H. L. (2002). Life history tradeoffs and phenotypic plasticity in the reproduction of Galapagos lava lizards (Microlophus delanonis). Oecologia 130, 44-52. doi: 10.1007/s004420100776

Klinkhamer, P. G., de Jong, T. J., and Metz, H. (1997). Sex and size in cosexual plants. Trends Ecol. Evol. 12, 260-365. doi: 10.1016/S0169-5347(97)01078-1

Koene, J. M. (2006). Tales of two snails: sexual selection and sexual conflict in Lymnaea stagnalis and Helix aspersa. Integr Comp Biol. 46, 419-429. doi: 10.1093/icb/icj040

Leonard, J. L. (2006). Sexual selection: lessons from hermaphrodite mating systems. Integr. Comp. Biol. 46, 349-367. doi: 10.1093/icb/icj041

Locher, R., and Baur, B. (2000). Mating frequency and resource allocation to male and female function in the simultaneous hermaphrodite land snail Arianta arbustorum. J. Evol. Biol. 13, 607-614. doi: 10.1046/j.1420-9101.2000.00206.x

Lorenzi, M. C., Schleicherová, D., and Sella, G. (2006). Life history and sex allocation in the simultaneously hermaphroditic polychaete worm Ophryotrocha diadema: the role of sperm competition. Integr. Comp. Biol. 46, 381-389. doi: 10.1093/icb/icj042

Lorenzi, M. C., and Sella, G. (2008). A measure of sexual selection in hermaphroditic animals: parentage skew and the opportunity for selection. $J$. Evo. Biol. 21, 827-833. doi: 10.1111/j.1420-9101.2008.01513.x

Mackiewicz, M., Tatarenkov, A., Turner, B. J., and Avise, J. C. (2006). A mixedmating strategy in a hermaphroditic vertebrate. Proc. $R$ Soc. Lond. B Biol. Sci. 273, 2449-2452. doi: 10.1098/rspb.2006.3594

Manriquez, P. H., and Castilla, J. C. (2005). Self-fertilization as an alternative mode of reproduction in the solitary tunicate Pyura chilensis. Mar. Ecol. Prog. Ser. 305, 113-125. doi: 10.3354/meps305113

Mary, C. M. S. (1994). Sex allocation in a simultaneous hermaphrodite, the blue-banded goby (Lythrypnus dalli): the effects of body size and behavioral gender and the consequences for reproduction. Behav. Ecol. 5, 304-131. doi: 10.1093/beheco/5.3.304

Michiels, N. K. (1998). Mating Conflicts and Sperm Competition in Simultaneous Hermaphrodites. San Diego: Academic Press.

Michiels, N. K., and Koene, J. M. (2006). Sexual selection favors harmful mating in hermaphrodites more than in gonochorists. Integr. Comp. Biol. 46, 473-480. doi: 10.1093/icb/icj043

Munday, P. L., Buston, P. M., and Wagner, R. R. (2006). Diversity and flexibility of sex-change strategies in animals. Trends Ecol. Evol. 21, 89-95. doi: 10.1016/j.tree.2005.10.020

Munday, P. L., Caley, M. J., and Jones, G. P. (1998). Bi-directional sex change in a coral-dwelling goby. Behav. Ecol. Sociobiol. 43, 371-377. doi: $10.1007 / \mathrm{s} 002650050504$

Pease, C. M., and Bull, J. J. (1988). A critique of methods for measuring life history tradeoffs. J. Evol. Biol. 1, 293-303. doi: 10.1046/j.1420-9101.1988.1040293.x

Petersen, C. W. (1990). Variation in reproductive success and gonadal allocation in the simultaneous hermaphrodite, Serranus fasciatus. Oecologia 83, 62-67. doi: 10.1007/BF00324635 
Petersen, C. W. (1991). Sex allocation in hermaphroditic sea basses. Am. Nat. 138, 650-667. doi: $10.1086 / 285240$

Petersen, C. W. (2006). Sexual selection and reproductive success in hermaphroditic seabasses. Integr. Comp. Biol. 46, 439-448. doi: $10.1093 /$ icb/icj045

Petersen, C. W., and Fischer, E. A. (1996). Intraspecific variation in sex allocation in a simultaneous hermaphrodite: the effect of individual size. Evolution 50, 636-645. doi: 10.1111/j.1558-5646.1996.tb03874.x

Policansky, D. (1982). Sex change in plants and animals. Annu. Rev. Ecol. Syst. 13, 417-495. doi: 10.1146/annurev.es.13.110182.002351

Premoli, M. C., and Sella, G. (1995). Sex economy in bethic polychaetes. Ethol. Ecol. Evol. 7, 27-48. doi: 10.1080/08927014.1995.9522968

Raimondi, P. T., and Martin, J. E. (1991). Evidence that mating group size affects allocation of reproductive resources in a simultaneous hermaphrodite. Am. Nat. 138, 1206-1217. doi: 10.1086/285278

Reznick, D. (1985). Costs of reproduction: An evaluation of the empirical evidence. Oikos 44, 257-267. doi: 10.2307/3544698

Roff, D. (1992). The Evolution of Life Histories: Theory and analysis. New York, NY: Chapman \& Hall.

Roff, D. A. (2002). Life History Evolution. Sunderland: Sinauer Associates.

Roff, D. A., and Fairbairn, D. J. (2007). The evolution of tradeoffs: where are we? J. Evol. Biol. 20, 433-447. doi: 10.1111/j.1420-9101.2006.01255.x

Ruxton, G. D., and Neuhäuser, M. (2010). When should we use one-tailed hypothesis testing? Methods Ecol. Evol. 1, 114-117. doi: 10.1111/j.2041-210X.2010.00014.x

Sagi, A., and Ra'anan, Z. (1988). Morphotypic differentiation of males of freshwater prawn Macrobrachium rosenbergii: changes in the midgut glands and the reproductive system. J. Crustac. Biol. 8, 43-47. doi: 10.2307/1548428

SAS. (2011). SAS/STAT Software; Version 9.3. Cary, NC: SAS Institute.

SAS. (2014). Using JMP 12. Cary, NC: SAS Institute Inc.

Schärer, L. (2009). Tests of sex allocation theory in simultaneously hermaphroditic animals. Evolution 63, 1377-1405. doi: 10.1111/j.1558-5646.2009.00 669.x

Schärer, L., Karlsson, L. M., Christen, M., and Wedekind, C. (2001). Sizedependent sex allocation in a simultaneous hermaphrodite parasite. J. Evol. Biol. 14, 55-67. doi: 10.1046/j.1420-9101.2001.00263.x

Schärer, L., and Ladurner, P. (2003). Phenotypically plastic adjustment of sex allocation in a simultaneous hermaphrodite. Proc. Roy. Soc. Lond. B Sci. 270, 935-941. doi: 10.1098/rspb.2002.2323

Schärer, L., and Pen, I. (2013). Sex allocation and investment into pre- and postcopulatory traits in simultaneous hermaphrodites: the role of polyandry and local sperm competition. Phil. Trans. R Soc. London Ser. B. 368:20120052. doi: 10.1098/rstb.2012.0052

Schärer, L., and Robertson, D. R. (1999). Sperm and milt characteristics and male v. female gametic investment in the Caribbean reef fish, Thalassoman bifasciatum. J. Fish. Biol. 55, 329-343. doi: 10.1111/j.1095-8649.1999.tb00682.x

Schärer, L., Sandner, P., and Michiels, N. K. (2005). Tradeoff between male and female allocation in the simultaneously hermaphroditic flatworm Macrostomum sp. J. Evol. Biol. 18, 396-404. doi: 10.1111/j.1420-9101.2004.00827.x

Schleicherová, D., Lorenzi, M. C., Sella, G., and Michiels, N. K. (2010). Gender expression and group size: a test in a hermaphroditic and a gonochoric congeneric species of Ophryotrocha (Polychaeta). J. Exp. Biol. 213, 1586-1590. doi: $10.1242 /$ jeb. 041814

Sella, G. (1990). Sex allocation in the simultaneously hermaphroditic polychaete worm Ophryotrocha diadema. Ecology 71, 27-32. doi: 10.2307/1940244

Shuster, S. M., and Wade, M. J. (2003). Mating Systems and Strategies. Princeton, NJ: Princeton University.

Stearns, S. C. (1992). The Evolution of Life Histories, 1st Edn. New York, NY: Oxford University.
Stephens, D. W., and Krebs, J. R. (1986). Foraging Theory: Monographs in Behavior and Ecology. Princeton, NJ: Princeton University.

Strathmann, R. R., Strathmann, M. F., and Emson, R. H. (1984). Does limited brood capacity link adult size, brooding, and simultaneous hermaphroditism? A test with the starfish Asterina phylactica. Am. Nat. 123, 796-818. doi: $10.1086 / 284240$

Tan, G. N., Govedich, F. R., and Burd, M. (2004). Social group size, potential sperm competition and reproductive investment in a hermaphroditic leech, Helobdella papillornata (Euhirudinea: Glossiphoniidae). J .Evol. Biol. 17, 574-580. doi: 10.1111/j.1420-9101.2004.00692.x

Tomiyama, K. (1996). Mate-choice criteria in a protandrous simultaneously hermaphroditic land snail Achatina fulica (Férussac) (Stylommatophora: Achatinidae). J. Moll. Stud. 62, 101-111. doi: 10.1093/mollus/62.1.101

Trouvé, S., Jourdane, J., Renaud, F., Durand, P., and Morand, S. (1999). Adaptive sex allocation in a simultaneous hermaphrodite. Evolution 53, 1599-1604. doi: 10.1111/j.1558-5646.1999.tb05423.x

van Noordwijk, A. J., and de Jong, G. (1986). Acquisition and allocation of resources: their influence on variation in life history tactics. Am. Nat. 128, 137-142. doi: 10.1086/284547

Vizoso, D. B., and Schärer, L. (2007). Resource-dependent sex-allocation in a simultaneous hermaphrodite. J. Evol. Biol. 20, 1046-1055. doi: 10.1111/j.1420-9101.2007.01294.x

Warner, R. R., Robertson, D. R., and Leigh, E. G. (1975). Sex change and sexual selection. Science 190, 633-638. doi: 10.1126/science.1188360

Weeks, S. C., Benvenuto, C., and Reed, S. K. (2006). When males and hermaphrodites coexist: a review of androdioecy in animals. Integr. Comp. Biol. 46, 449-464. doi: 10.1093/icb/icj048

Weeks, S. C., Benvenuto, C., Reed, S. K., Duff, R. J., and Duan, Z. H. (2014). A field test of a model for the stability of androdioecy in the freshwater shrimp, Eulimnadia texana. J. Evol. Bio. 41, 251-261. doi: 10.1007/s11692-013-9265-0

West, S. (2009). Sex allocation. Princeton, NJ: Princeton University.

Wilson, K., and Hardy, I. C. W. (2002). "Statistical analysis of sex ratios: an introduction," in Sex Ratios: Concepts and Research Methods, ed I. C. W. Hardy (Cambridge: Cambridge University), 48-92

Worley, A. C., Houle, D., and Barrett, S. C. (2003). Consequences of hierarchical allocation for the evolution of life-history traits. Am. Nat. 161, 153-167. doi: $10.1086 / 345461$

Zhang, D., and Lin, J. (2005). Comparative mating success of smaller malephase and larger male-role euhermaphrodite-phase shrimp, Lysmata wurdemanni (Caridea: Hyppolytidae). Mar. Biol. 147, 1387-1392. doi: 10.1007/s00227-005-0029-y

Zhang, D., and Lin, J. (2006). Mate recognition in a simultaneous hermaphroditic shrimp, Lysmata wurdemanni (Caridea: Hippolytidae). Anim. Behav. 71, 1191-1196. doi: 10.1016/j.anbehav.2005.10.005

Zhang, D., Shengli, C., Liu, H., and Lin, J. (2008). Antennal sensilla in the genus Lysmata (Caridea). J. Crustac. Biol. 28, 433-438. doi: 10.1651/07-2876R.1

Zucker, N., Cunningham, M., and Adams, H. P. (1997). Anatomical evidence for androdioecy in the clam shrimp Eulimnadia texana. Hydrobiologia 359, 171-5. doi: 10.1023/A:1003158719289

Conflict of Interest Statement: The author declares that the research was conducted in the absence of any commercial or financial relationships that could be construed as a potential conflict of interest.

Copyright $\odot 2018$ Baeza. This is an open-access article distributed under the terms of the Creative Commons Attribution License (CC BY). The use, distribution or reproduction in other forums is permitted, provided the original author(s) and the copyright owner(s) are credited and that the original publication in this journal is cited, in accordance with accepted academic practice. No use, distribution or reproduction is permitted which does not comply with these terms. 